\title{
CRIANDO VANTAGEM COMPETITIVA NO MERCADO INTERNACIONAL: ALIANÇAS ESTRATÉGIAS NA LOGÍSTICA DE EXPORTAÇÃO - UM ESTUDO DE CASO
}

\section{CREATING COMPETITIVE ADVANTAGE IN INTERNATIONAL MARKETING: STRATEGIC ALLIANCES AT EXPORTATION \\ LOGISTICS - A CASE STUDY}

\author{
Leonel Mazzali \\ Professor Universitário \\ Mestrado Interdisciplinar em Educação, Administração e Comunicação \\ Universidade São Marcos \\ Rua João Antonio de Campos, 40, Jundiaí, SP, CEP 13.209-280 \\ (011-97952727) leonel_mazzali@uol.com.br
}

\section{Milton Camargo Junior}

Supervisor de exportação e exportação da Cia Cacique de Café Solúvel e professor do Centro Universitário Monte Serrat (UNIMONTE), em Santos- SP

Rua Luiz Rodrigues Pedro, 177, Guarujá, SP, CEP 11441-320

(013-339823620) miltoncamargo@ cacique.com.br

RESUMO

O trabalho analisa o processo de criação da vantagem competitiva na economia internacional, a partir do conceito de gestão da cadeia de suprimentos. Em primeiro lugar, o objetivo é mostrar que o sucesso no mercado internacional depende da formação de alianças estratégicas. Em segundo lugar, a formação das alianças demanda a adaptação de estratégias e culturas das organizações envolvidas. Optou-se por uma pesquisa qualitativa de caráter 
descritivo, associada ao relato da experiência de um grupo de executivos da Companhia Cacique de Café Solúvel e de seus parceiros, sobre a constituição de uma aliança logística no comercio internacional. Ficou patente, de um lado, que a aliança entre a empresa e seus parceiros consolidou uma visão da interdependência estratégica no interior da cadeia de suprimentos. De outro, o sucesso de uma aliança está baseado na identificação e seleção de parceiros, no efetivo alinhamento de interesses e de estratégias, na construção da confiança, no tratamento igualitário e na transparência na negociação.

Palavras-chave: logística de exportação; alianças estratégicas; vantagem competitiva

\begin{abstract}
This paper analyses the creation process of a competitive advantage in the international business, starting on the concept of the supply chain management. First, the aim of this study is to show that the dimension of the success in the international negotiations depends on the formation of strategic alliances. Second, that the formation of the alliances demands the adaptation of cultures and strategies of all the involved parties. It was opted for a qualitative research, with descriptive character, associated to the experience of an executives group of the Cia Cacique de Café Solúvel and its partners, on the constitution of a logistic alliance. It is clearly shown, on one hand, that the alliance between the main company and its partners consolidates the necessity of strategic interdependence in the interior of the supply chain. On the other hand, the success of it is based on the identification and selection of the partners, the effective alignment of interests and strategies, the construction of the confidence, the equal treatment and transparence in the negotiation.
\end{abstract}

Key-words: export logistics; strategic alliances; competitive advantage 


\section{INTRODUÇÃO}

Em uma economia globalizada, a conquista da competitividade internacional por parte das empresas é um desafio crescente, em particular os associados ao processo de negociação e distribuição de produtos e serviços em escala mundial. Nesse contexto, como colocam Wilkinson, Mattsson e Easton (2000), a competitividade de uma empresa não pode ser avaliada somente a partir da consideração de seu potencial interno, vis a vis as demais participantes do mercado. Faz-se necessário um contexto analítico mais amplo: a gestão da cadeia de suprimentos, proposto por Bowersox, Mentzer e Speh (1995) e Innis e LaLonde (1994). Embora não exista consenso sobre o conceito de gestão da cadeia de suprimentos, a sua estrutura básica, na visão de Macpherson (2001), se apóia nas transações e nas relações entre e no interior de organizações. A constituição de relacionamentos (relação fornecedorcliente) estreitos entre o conjunto de empresas integrante de uma cadeia produtiva é o foco primordial para a obtenção do desejado alinhamento entre atividades e estratégias.

De acordo com essa perspectiva, o desempenho de uma empresa, de modo especial no mercado internacional, depende não somente de sua estratégia e recursos (competências), mas também de maneira decisiva das estratégias e recursos de outras organizações que lhe são complementares - direta ou indiretamente. Nenhuma empresa, mesmo a mais integrada num sistema de articulação em cadeia, possui todas as competências necessárias à execução do conjunto de atividades produtivas. Todas as empresas devem, no mínimo, considerar e, se necessário ou conveniente, apoiar-se nas competências no âmbito de outras empresas, especialmente na medida em que essas competências se diferenciam daquelas de seu domínio.

Nesse contexto, as empresas especializadas no fornecimento de serviços logísticos são fundamentais. À medida que as empresas se tornam globais, nos âmbitos do fornecimento, da produção e da distribuição, a administração da cadeia de suprimento se torna mais complexa em termos da competência logística. As empresas especializadas em logística, com presença global e com capacidade para administrar diferenças culturais e legais, podem auxiliar as empresas a se expandir geograficamente, aproveitando vantagens derivadas de economias de escala e reduzidos prazos de entrega.

$\mathrm{Na}$ verdade, o caráter crítico assumido pela variável "tempo" trouxe novos desafios estratégicos impossíveis de serem enfrentados no interior das fronteiras de uma organização. Assim este trabalho pretende-se mostrar, em primeiro lugar, que o sucesso no mercado internacional depende crucialmente do desenvolvimento e da gestão das relações com outras 
organizações integrantes da cadeia de suprimentos, em especial, daquelas responsáveis pela estrutura logística. Em segundo lugar, mostrar que a formação dessas alianças exige um processo peculiar de construção, visando a adaptação das estratégias e das culturas das organizações.

Optou-se por uma pesquisa qualitativa de caráter descritivo, a partir da utilização de um estudo de caso, associado à experiência de constituição de uma aliança estratégica no comércio internacional, em cujo centro situa-se a Companhia Cacique de Café Solúvel. .

A Companhia Cacique de Café Solúvel é líder do setor. Com produção de aproximadamente 70 toneladas/dia de café solúvel, a empresa exporta para mais de 40 países, tendo como mercado principal o Leste Europeu, para o qual destina 50\% de sua produção, seguido pelos EUA e pelo Japão, que adquirem, respectivamente, $30 \%$ e $15 \%$ da produção. A partir de meados de 1996, a empresa encontrou uma dificuldade crescente na manutenção da vantagem competitiva em seu principal mercado - Leste Europeu -, em especial a Rússia, levando ao aprofundamento da análise da cadeia de suprimentos e da reconfiguração do relacionamento com os principais agentes fornecedores de serviços logísticos.

O trabalho está estruturado em quatro seções. A primeira apresenta a logística como uma competência construída no interior de um conjunto de relacionamentos entre os agentes integrantes da cadeia produtiva, conformando uma rede estratégica de suprimentos. A segunda, após aprofundar a discussão sobre os conceitos de aliança estratégica e de aliança logística, contempla uma metodologia de análise do processo de constituição dessa forma peculiar de relacionamento entre empresas. A terceira discute os procedimentos metodológicos associados à pesquisa realizada junto a uma empresa líder na exportação de café solúvel. A quarta apresenta e analisa a experiência da referida empresa na construção de uma rede de distribuição no mercado do Leste Europeu, a partir da formação de alianças estratégicas com os principais fornecedores de serviços logísticos na região. Finalmente, a conclusão, as limitações e as propostas para futuras pesquisas.

\section{LOGISTICA, GESTÃO DA CADEIA DE SUPRIMENTOS E VANTAGEM COMPETITIVA}

O referencial da RBV - Resource-Based View of the Firm (visão da empresa sob a perspectiva de recursos) - o qual visualiza as empresas como conjuntos muito diferentes de ativos e de capacidades tangíveis e intangíveis (competências), abre novas possibilidades para 
o entendimento da inserção da logística na estratégia competitiva. O fundamental é que, segundo o referido referencial, para serem considerados estratégicos, os recursos devem ser específicos à empresa e, portanto, valiosos, escassos e imperfeitamente imitáveis, gerando renda e vantagem competitiva. (BARNEY, 1991; SCHOEMAKER e AMIT, 1994)

Olavarrieta e Ellinger (1997) afirmam que a logística pode ser considerada como um recurso (competência) estratégico, especificamente porque é valioso, difícil e custoso de imitar. Mais precisamente, tendo por referência o arcabouço conceitual proposto por Lavie (2006) e por Winter (2003), a competência logística permite à empresa integrar eficientemente recursos e implementar estratégias que, além de proporcionar criação de valor para o consumidor, no âmbito das utilidades de tempo, lugar e posse, aumentam a performance, exploram as oportunidades de mercado e neutralizam a ameaça de entrada.

A partir do conceito do Council of Logistics Management: "Logística é o processo de planejamento, implementação e controle do fluxo e armazenagem de bens, serviços e informações, do ponto de origem ao ponto de consumo.“(FRANKEL, WHIPPLE E FRAYER, 1996, p.48), percebe-se que, enquanto competência estratégica, a logística envolve uma complexa combinação de ativos físicos, rotinas organizacionais, habilidades e conhecimentos, os quais requerem tempo para desenvolvimento e integração. Adicionalmente, requer a constituição de relacionamentos com fornecedores, distribuidores e clientes, implicando na ampliação da gestão logística para além das fronteiras de uma única organização, o que remete a discussão para o conceito de gestão da cadeia de suprimentos.

A gestão da cadeia de suprimentos tem por objetivo aproveitar as vantagens da especialização dos agentes envolvidos, em conjunto com as vantagens da coordenação e do controle propiciados pela organização verticalmente integrada. A importância estratégica da colaboração entre fornecedor e cliente, com o objetivo de criar um enfoque integrado na cadeia de suprimentos foi identificada por Carlisle e Parker (1989), os quais afirmam que as tradicionais relações adversas fornecedor/cliente contêm contradições, servindo somente para criar vantagens temporárias. Os autores sugerem que o "enfoque do jogo de soma zero" nas relações é limitado e que a colaboração pode gerar benefícios - diretos e indiretos - muito maiores.

O enfoque da gestão da cadeia de suprimentos transformou a visão tradicional acerca da construção e da manutenção da vantagem competitiva. A performance de uma determinada organização não depende somente das habilidades, recursos e competências individuais, mas das habilidades, recursos e competências das demais organizações que integram o sistema de 
relações imanentes à cadeia de suprimentos. (JOHANSON e MATTSSON, 1994) Essas outras organizações incluem fornecedores de materiais, de componentes, de maquinários, de equipamentos e serviços técnicos; distribuidores; intermediários e clientes.

Cada agente integrante da cadeia controla recursos e os utiliza para desempenhar atividades de produção e de distribuição. Na verdade, na visão de Ford et al. (1993), os inputs e os recursos acessados externamente representam uma parcela significativa, se não a maior, do custo total e das atividades de criação de valor. A coordenação do fluxo de materiais, serviços e de informações, no âmbito da cadeia como um todo, deve ser assegurada, de modo que a cooperação entre os agentes, ao consolidar as relações interorganizacionais, transformase na base da competitividade.

O campo de estudo conhecido como gestão da cadeia de suprimentos emergiu, com toda força, segundo Ford (1980), a partir de 1980, quando os benefícios provenientes da cooperação nas relações entre os agentes da cadeia produtiva foram identificados. Desde então, foram propostas várias definições, destacando-se a de Ellram e Cooper (1993, p.3), a qual sugere que a gestão da cadeia de suprimentos é "uma filosofia integradora da administração do fluxo de um canal de distribuição, do fornecedor até o consumidor final”.

O conceito de gestão da cadeia de suprimentos está centrado em um processo de reestruturação organizacional, que se estende ao desenvolvimento de uma ampla cultura de colaboração, mas que enfatiza um forte sentido de integração (coordenação e controle) de todas as atividades, visando a sincronização do fluxo de produção. Para Tokman et al.(2007), as relações apoiadas na cooperação são a estratégia nuclear da cadeia de suprimentos. Da mesma forma, na visão de Min e Mentzer (2004), à medida que o foco estratégico de uma empresa se desloca na direção de um portfólio estratégico composto por diversas relações, a gestão de múltiplas interações com outras organizações se transforma em uma competência essencial. Significa dizer, de acordo com Cox (2004), que só se pode falar em gestão da cadeia de suprimentos com a configuração de um relacionamento pró-ativo entre fornecedor e cliente.

É importante considerar as dificuldades para a obtenção da colaboração entre as organizações, em particular as incertezas e a inabilidade na coordenação de várias atividades e parceiros, conforme análise detalhada procedida por Holweg e Bicheno (2002). A efetivação de relações com outras organizações requer tempo e recursos associados à criação da confiança entre as partes interessadas, ao desenvolvimento de canais de comunicação e à integração entre atividades e processos. Desse modo, na visão de Hoyt e Huq (2000) e de 
Croom (2001), a especificidade do processo de gestão das relações entre as organizações integrantes da cadeia de suprimentos dá origem a uma vantagem competitiva. .

\section{ALIANÇAS ESTRATÉGICAS E GESTÃO DA CADEIA DE SUPRIMENTOS}

Noleto (2000) faz distinção entre os conceitos de parceria e aliança. A parceria significa uma associação entre fornecedor/cliente, na qual a soma das partes representa mais do que o somatório individual. A aliança expressa a associação entre empresas, buscando a conquista de melhores posições e objetivos. Para a autora, a lógica da parceria é a da intercomplementaridade de recursos e de capacidades entre organizações, enquanto que, nas alianças, "organizações que poderiam atuar de forma independente diante de uma determinada questão decidem fazê-lo conjuntamente, motivadas pela consciência da magnitude e complexidade da ação a ser empreendida.” (NOLETO, 2000, p 15)

Como se percebe, a parceria se assenta na união entre empresas que, de alguma forma, complementam as atividades umas das outras, enquanto que a aliança sugere que empresas, com capacidades próprias, por terem objetivos estratégicos compatíveis, se unem para atingílos de forma excelente.

Todavia, a despeito das diferenças, um ponto comum faz com que os dois conceitos tenham o mesmo grau de importância no mercado globalizado - o efeito sinérgico -, que faz com que o resultado da união seja maior do que o alcançado por uma das partes agindo individualmente. A propósito, Bowersox (1990) descreve as alianças logísticas como um compacto especial de negócios, onde as partes se beneficiam da sinergia associada ao trabalho conjunto. Os relacionamentos se caracterizam por elevados níveis de confiança, cooperação, dependência e compartilhamento de benefícios e riscos.

Para Frankel, Whipple e Frayer (1996), uma aliança reflete um processo onde os participantes desejam modificar suas práticas básicas de negócio, reduzindo a duplicação e o desperdício, aumentando, ao mesmo tempo, a performance.

Esse trabalho examina as alianças estratégicas voltadas para a redução do desperdício e da duplicidade, no interior da cadeia de suprimentos, a partir da otimização das atividades logísticas entre as organizações parceiras. Dessa perspectiva, as alianças logísticas têm como foco o desejo dos parceiros de modificar o processo logístico - movimentação, armazenagem, serviços e informações relacionados -, com o objetivo de aumentar a eficiência e a eficácia do atendimento ao cliente. Dentre os benefícios obtidos, cabem menção a redução de custos a 
partir da especialização; o aumento da performance, a partir da obtenção de maior sinergia nas atividades; o aumento da informação que suporta o planejamento e a redução do risco e da incerteza.

Neste trabalho, uma aliança logística será definida como: um arranjo cooperativo relativamente duradouro entre uma empresa compradora e uma empresa fornecedora de serviços logísticos. Essa definição contém seis aspectos chave, apontados por Cooke (1994), LaLonde e Cooper (1989) e Bowersox et al. (1989). Em primeiro lugar, as alianças logísticas são relacionamentos interorganizacionais com uma orientação de longo prazo e não de curto prazo. Em segundo lugar, as alianças logísticas exigem cooperação entre as partes, a partir do compartilhamento de informações e dos benefícios gerados pela relação. Finalmente, os detalhes do arranjo podem variar amplamente dependendo das necessidades do comprador e das capacidades do fornecedor.

Knemeyer e Murphy (2005) e Stefansson (2006) aprofundaram a análise das relações entre o usuário e o fornecedor dos serviços logísticos, concluindo que a confiança e o comprometimento entre os parceiros são os elementos centrais do sucesso das alianças logísticas. LaLonde e Cooper (1989) observaram que, na maioria dos setores, as relações se transformaram de orientadas para as transações para orientadas para o contrato. Ademais, alguns relacionamentos evoluem ao longo do tempo, na direção de parcerias ou alianças, à medida que a confiança se desenvolve entre as partes. Gardner e Cooper (1988) afirmam que as alianças logísticas vão além da mera transação e, tipicamente, evoluem ao longo do tempo. Ambas as partes são motivadas a gerenciar o risco e a incerteza, a partir da cooperação, possibilitando um benefício maior do que aquele obtido a partir da integração vertical.

Bowersox (1990) acredita que a consolidação da aliança e o desenvolvimento da confiança não são fáceis de obter, considerando as relações adversas entre comprador e vendedor. LaLonde e Cooper (1989) acreditam ser necessária uma mudança significativa na cultura dos parceiros na direção da visualização da importância do relacionamento à longo prazo.

Assim, embora as alianças e as parcerias possam gerar resultados com alto valor para as partes interessadas, elas precisam ser construídas e acompanhadas com cuidado e atenção. A propósito, Gooley (2005) identifica um grande número de problemas que os fornecedores de serviços logísticos têm que enfrentar, em particular, pressões por parte dos usuários sobre o preço e sobre a necessidade de ampliar o campo dos serviços oferecidos. Ademais, os clientes 
exigem investimentos em novas tecnologias, como sistemas de rastreamento e monitoramento por satélite. .

Nesse âmbito, Harbison e Pekar (1999) propõem uma metodologia específica para a formação de alianças estratégicas. Após a definição das estratégias e dos objetivos, existem seis passos a serem seguidos antes da implementação propriamente dita: seleção dos parceiros, avaliação dos fatores negociáveis e da alavancagem, definição das oportunidades, avaliação do impacto sobre os acionistas, avaliação do poder de barganha e negociação (planejamento da integração).

Quando a empresa tiver uma visão clara da estratégia e dos objetivos da aliança, deve então iniciar a identificação e a seleção dos candidatos potenciais, tendo em vista, não apenas as competências e a posição que os mesmos possuem no mercado, mas principalmente, a cultura e o histórico de outras alianças que estes mantêm ou tenham mantido no mercado.

Após a definição dos parceiros potenciais, torna-se necessária uma avaliação mais profunda das competências e das contribuições individuais para a aliança. Lorange e Roos (1995) denominam esta fase de "análise da combinação estratégica", envolvendo um processo político e analítico gradual, complexo e combinado entre as partes. Um dos pontos importantes a ser avaliado é quais são as capacidades diferenciais possuídas pelos parceiros potenciais.

Na avaliação dos fatores negociáveis e da alavancagem, Doz e Hamel (2000) chamam a atenção para a necessidade da compatibilidade das estratégicas, pois a estabilidade de uma aliança é determinada pela adequação das posições estratégicas dos parceiros ao perfil de criação de valor da aliança.

No que se refere à definição das oportunidades, é essencial para o sucesso da aliança, pois proporciona a quantificação do esforço necessário e dos benefícios almejados. Da mesma forma, a avaliação do impacto da aliança sobre os interesses dos acionistas.

Antes de entrar na fase de negociação propriamente dita, é necessário que se avalie o poder de barganha dos agentes, considerando:

- a definição clara das contribuições essenciais necessárias para formar uma aliança de sucesso;

- a proteção dos recursos centrais da empresa, deixando claro para um parceiro potencial quais são eles e por que se quer protegê-los;

- $\quad$ o estilo de negociação e os antecedentes do parceiro, analisando outras alianças que a empresa tenha feito; 
- o interesse dos potenciais parceiros pela aliança, em termos dos benefícios estratégicos e não-estratégicos visados;

- o tipo e a dimensão de recursos e o compromisso que o parceiro potencial trará para a aliança.

Finalmente, a fase de planejamento da integração requer que os parceiros entendam a capacidade e as forças conjuntas resultantes da união. Deve-se também assegurar que haja entusiasmo e cooperação em toda a organização. Três aspectos são de fundamental importância: atribuição de tarefas entre os parceiros, definição das fronteiras da aliança e a definição clara dos procedimentos de dissolução, das penalidades e das obrigações, em caso de desistência de uma das partes.

\section{PROCEDIMENTOS METODOLÓGICOS}

Considerando-se os objetivos da pesquisa - mostrar a importância das alianças estratégicas para a construção de vantagens competitivas, no âmbito do comércio internacional, e analisar o processo de constituição das mesmas - optou-se por uma pesquisa qualitativa de caráter descritivo, a partir da utilização de um estudo de caso (Yin, 2001), associado à experiência de constituição de uma aliança estratégica no comercio internacional, em cujo centro situa-se a Companhia Cacique de Café Solúvel.

Cabe destacar que o enfoque qualitativo foi adotado tendo em vista a riqueza dos dados (Miles e Huberman, 1994) obtidos a partir de entrevistas com os executivos envolvidos, permitindo a coleta de informações com maior profundidade e, por conseqüência, a melhor compreensão do contexto onde foi tomada a decisão. É importante ressaltar que a obtenção de dados ocorreu a partir do contato direto e interativo dos pesquisadores com a situação objeto de estudo, uma vez que um deles integrou o grupo executivo da Cia Cacique de Café Solúvel responsável pela gestão da parceria.

As entrevistas foram elaboradas de forma semi-estruturada e não disfarçada, a partir de roteiro prévio. Foram selecionados para a entrevista um executivo representante da Cia Cacique de Café Solúvel e mais cinco executivos das empresas que fizeram parte do processo de constituição da aliança estratégica voltada à logística de exportação para o Leste Europeu. Por respeito às solicitações dos representantes das empresas parceiras da Cacique, os nomes das mesmas, bem como de seus representantes, com exceção da própria Cacique, foram omitidos. 
A entrevista com o executivo da Cacique girou em torno dos seguintes aspectos: motivação para a constituição da aliança; processo de identificação e seleção dos parceiros; objetivos visados; relação custo/beneficio; contribuição dos parceiros e contrapartida da Cacique; preocupação com a proteção de recursos estratégicos; estilo de negociação e razões que levaram os parceiros a negociar.

A entrevista com os executivos das empresas parceiras abordou os seguintes aspectos: razões que levaram à aliança com a Cacique; natureza e tipo das competências aportadas; necessidade de proceder a alianças adicionais; contrapartida da Cacique; preocupação com a proteção de recursos estratégicos e estilo de negociação.

Com relação aos procedimentos relativos ao tratamento dos dados qualitativos, foi utilizada uma estratégia analítica denominada por Yin (2001, p. 140) de "construção da explanação", isto é, "o objetivo é analisar os dados do estudo de caso, construindo uma explanação sobre o caso." Mais precisamente, o pesquisador analisa detalhadamente o discurso dos entrevistados, obtido por meio de entrevistas, examinando os acontecimentos (natureza do contexto e das decisões) para, em seguida, elaborar a explanação do processo de formação da aliança estratégica entre a Cacique e seus prestadores de serviços logísticos.

Esse é um procedimento freqüente nas pesquisas qualitativas. Como afirma Neves:

Nas pesquisas qualitativas, é frequente que o pesquisador procure entender os fenômenos, segundo a perspectiva dos participantes da situação estudada e a partir daí, situe sua interpretação dos fenômenos estudados. (NEVES, 1996, p. 1)

Ademais, ainda segundo o referido autor:

O vínculo entre signo e significado, conhecimento e fenômeno, sempre depende do arcabouço de interpretação empregado pelo pesquisador, que lhe serve de visão do mundo e de referencial. (NEVES, 1996, p. 2)

Nessa direção, a proposição teórica central orientadora da análise e interpretação dos dados obtidos, sustentada pela revisão da literatura, é a de que "a confiança e o comprometimento entre os parceiros são os elementos centrais do sucesso das alianças logísticas”.

\section{CONSTRUINDO UMA REDE DE DISTRIBUIÇÃO NO LESTE EUROPEU - A EXPERIÊNCIA DA COMPANHIA CACIQUE DE CAFÉ SOLÚVEL}


A Companhia Cacique de Café Solúvel é líder do setor. Com produção de aproximadamente 70 toneladas/dia de café solúvel, a empresa exporta para mais de 40 países, tendo como mercado principal o Leste Europeu, para o qual destina 50\% de sua produção, seguido pelos EUA e pelo Japão, que adquirem, respectivamente, $30 \%$ e $15 \%$ da produção.

A partir de meados de 1996, a empresa encontrou uma dificuldade crescente na manutenção da vantagem competitiva em seu principal mercado - Leste Europeu -, em especial a Rússia. Detectou-se que o tempo gasto entre a colocação do pedido, a produção, o embarque e os transbordos até a entrega aos importadores locais correspondia a 50 dias. Esse período demasiadamente longo demandava, além de programação eficiente das compras pelos importadores, a manutenção de estoque, visando a disponibilização do produto na época adequada de consumo. Ressalte-se que, face ao elevado risco de inadimplência apresentado pela região (country risk), o importador tinha que adiantar o valor das suas compras.

A figura 1 apresenta a configuração da cadeia de suprimentos até 1999, quando foi implementada a aliança estratégica.

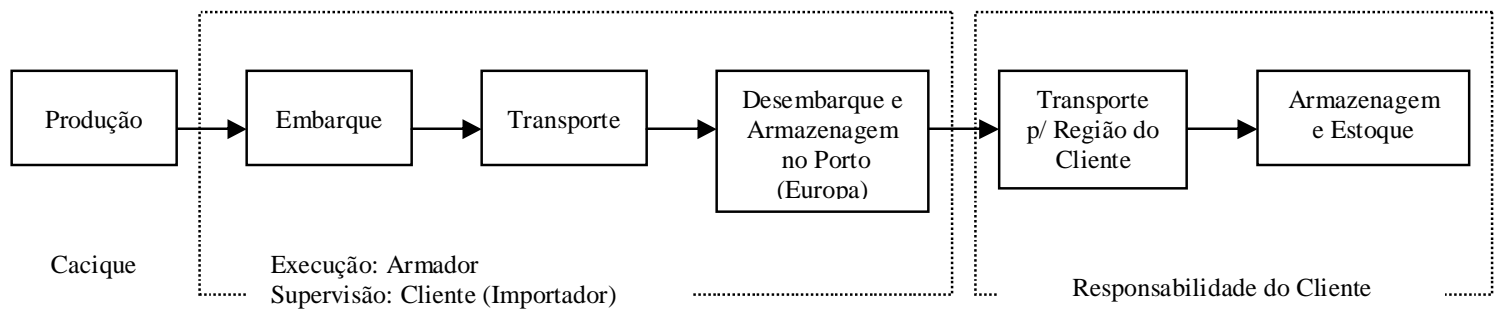

Figura 1 : Configuração da Cadeia de Suprimentos até 1999

Fonte: elaboração dos autores

Diante desse contexto, os importadores passaram a dar preferência aos principais concorrentes. Empresas multinacionais com estratégia de distribuição de produtos em tempo real apoiada na implantação de unidades de produção, unidades embaladoras, ou ainda armazéns para estoque e distribuição pelo sistema de pronta entrega.

\subsection{DEFINIÇÃO DA ESTRATÉGIA E DOS OBJETIVOS}

A Cacique, a princípio, inclinou-se a "copiar" a estratégia da concorrência, direcionando estudos para analisar a viabilidade da implantação de uma filial na região. Esses estudos, porém, mostraram, de um lado, a necessidade de um volume considerável de 
investimento e, de outro, as dificuldades associadas à transferência de tecnologia e a adaptação às normas culturais e legais da região. Em síntese, chegou-se à conclusão de que essa forma de expansão da empresa apresentava muitos riscos e nenhuma vantagem competitiva.

A Diretoria de Exportação da Cacique, responsável pela logística de distribuição, resolveu, então, analisar a viabilidade da constituição de alianças estratégicas com os prestadores de serviços de transporte (armadores) para o Leste Europeu. Os principais parâmetros balizadores da alternativa foram:

a) implantação de uma infra-estrutura de armazenagem na região, de modo a permitir a reposição constante do estoque dos clientes;

b) o ponto de entrada para a Rússia deveria ser a Finlândia ((Portos de Hamina e Kotka), pois o porto de São Petsburgo, situado na Rússia, não era aceito pelos clientes, por razões alfandegárias;

c) monitoramento dos custos logísticos, tendo em vista o acirramento da concorrência;

d) o café solúvel deveria permanecer no interior dos contêineres, devidamente lacrados, até o momento da retirada pelos clientes, com objetivo de evitar roubo de carga.

Essa alternativa, segundo o diretor de exportação da Cacique, apresentava três importantes vantagens: exploração das economias de escala na produção da fábrica no Brasil; ampliação do controle dos custos de transação associados ao tempo logístico - pedido, movimentação, transbordo, armazenagem e transporte - e, finalmente, a entrega do produto na unidade de comercialização do importador.

A figura 2 apresenta a configuração da cadeia de suprimentos, a partir da constituição das alianças estratégicas como os armadores, em 1999.

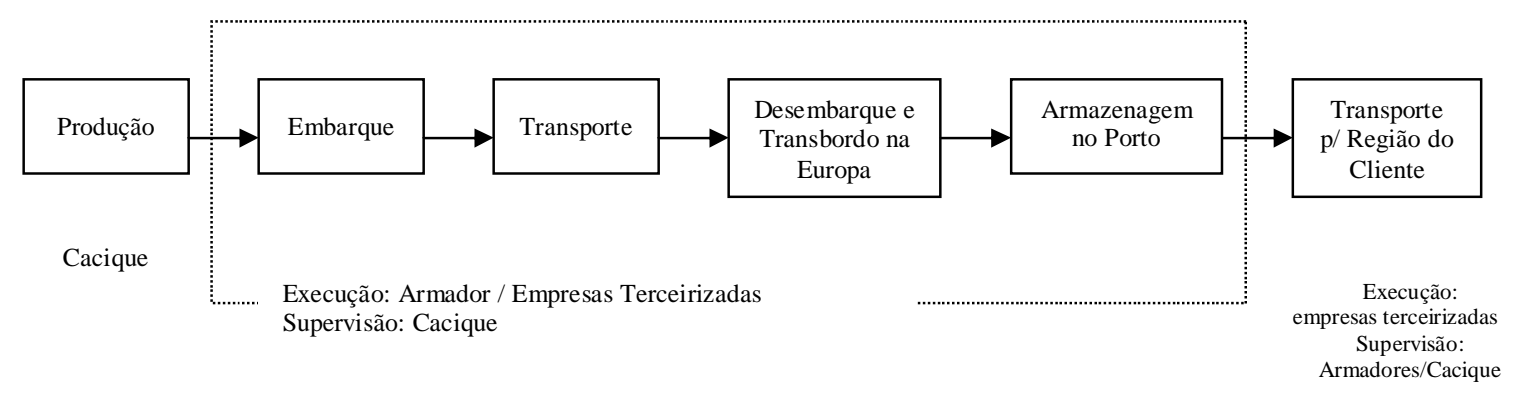


Figura 2: Configuração da Cadeia de Suprimentos a partir da constituição das Alianças Estratégicas

Fonte: elaboração dos autores 
Como se percebe, caberia aos armadores desempenhar direta ou indiretamente:

a) o transporte marítimo dos contêineres até a Finlândia (Portos de Hamina e Kotka), com transbordo em algum porto da Europa;

b) a armazenagem e demurrage livres por um período de 30 a 45 dias no porto;

c) o transporte rodoviário para Moscou - principal destino - ou rodoferroviário para outros destinos do Leste Europeu;

d) a administração dos contêineres e dos transbordos necessários até a entrega da carga ao cliente, mediante autorização por escrito da empresa;

e) a administração das taxas de armazenagem e de demurrage para as unidades que permanecerem mais tempo do que o concedido nos portos de transbordo e ou na Finlândia;

f) a manutenção de um sistema de informações eficiente para acompanhamento, em tempo real, das movimentações desde o embarque até a entrega ao cliente; e

g) seguro internacional para cobrir a operação de transporte desde o embarque da mercadoria ate a entrega ao cliente final. .

Cabe destacar que a Cacique seria responsável pelo investimento nos estoques situados na região, sendo que os custos associados à armazenagem deveriam ser gerenciados pelos parceiros.

\subsection{IDENTIFICAÇÃO E SELEÇÃO DOS PARCEIROS}

Foram convidados os armadores e todos os agentes - empresas contratadas pelos armadores para representá-los em determinadas regiões - que atendem a região do Leste Europeu, para que pudessem, tendo interesse, desenvolver alianças com a Cacique.

Além dos objetivos acima, a Cacique colocou de forma clara que "a perda da competitividade no mercado russo certamente traria resultados negativos não só para a Cacique, mas também para os armadores (transportadores)”.

Das cinco empresas prestadoras de serviço na região, três foram selecionadas, aqui denominadas de Global, ff Alfa e ff Beta, para integrar a aliança, as quais, além do interesse, apresentaram estratégias compatíveis com as da Cacique. Dentre as razões apresentadas pelas empresas que acabaram por se tornar parceiras, destacam-se as seguintes:

a) ter uma empresa do porte da Cacique e com marca reconhecida em sua lista de parceiros; 
b) desenvolvimento de novas competências no mercado russo, extremamente promissor; e

c) como a Cacique embarca grande quantidade de contêineres durante todo o ano, torna-se viável a reposição dos mesmos no Leste Europeu, especialmente por ser o café um produto leve, otimizando a utilização do espaço do navio.

Cabe destacar que, pela expressiva liderança que a Cacique mantém em seu segmento, embarcando grandes quantidades de contêineres durante todo o ano, torna-se atrativa para a maioria dos armadores e outros intervenientes na navegação marítima. De acordo com o executivo da Cacique, os parceiros foram "qualificados" através de visitas às instalações, visando atender às normas ISO 9000, mais especificamente quanto ao requisito 4.15, que trata da logística - manuseio, armazenamento, embalagem, preservação e expedição.

\subsection{AVALIAÇÃO DOS FATORES NEGOCIÁVEIS E DA ALAVANCANGEM}

Com o sistema anterior à concretização da aliança, a Cacique não tinha o controle total da operação até a entrega da carga ao cliente (importador). A carga era entregue nas mãos de um transportador, sendo que a empresa acompanhava o trânsito da mercadoria até a chegada ao destino final. Recaia também sobre o cliente o controle de todo o procedimento alfandegário e de transporte, pois já havia adiantado o pagamento da carga. Agregue-se, ademais, o fato de ter de aguardar por aproximadamente 50 dias, até a conclusão do processo.

Com a aliança, como mostra a figura 2, a Cacique passou a ter o controle total da operação logística, uma vez que continua sendo a proprietária da carga até a Finlândia (Portos de Hamina e Kotka). O cliente, por sua vez, passou a adquirir o produto diretamente do armazém situado nesse país, recebendo a mercadoria em, no máximo, dois dias, eliminando, portanto, a necessidade de manter estoques.

Na visão do executivo da Cacique: "a aliança propiciou que os três elementos exportador, segmento logístico e clientes - mantivessem suas atenções voltadas apenas para aquilo que realmente fazem com excelência”.

De acordo com o executivo da empresa Global, "a aliança fez com que uma nova visão fosse incorporada às pessoas chave dentro da empresa, uma vez que começaram a perceber a importância de ajudar a Cacique a manter a competitividade."

Segundo o executivo da empresa ff Alfa: "Ajudar a Cacique a aumentar a competitividade no mercado do Leste Europeu significa que ela vai vender mais e, conseqüentemente, eи vou embarcar mais.” 


\subsection{DEFINIÇÃO DAS OPORTUNIDADES DE NEGÓCIOS}

Para as empresas Global e ff Beta, as oportunidades de negócio estavam associadas a sua capacidade de adaptação às necessidades da Cacique, seu principal cliente, além da viabilidade da reposição de contêineres, na Europa. A empresa ff Alfa, por sua vez, buscava há algum tempo um parceiro que justificasse a construção de uma solução logística para o Leste Europeu. De acordo com o executivo da empresa "precisávamos mais do que um ou alguns clientes para justificar uma estrutura logística para aquela região. A aliança com a Cacique, devido ao volume exportado e à consolidação no mercado russo, foi exatamente o que necessitávamos para viabilizar a operação.”

\subsection{AVALIAÇÃO DO IMPACTO SOBRE OS ACIONISTAS}

De acordo com o gerente de exportação da Cacique, foi feita a avaliação do impacto sobre os acionistas, quando a empresa estava em dúvida quanto à montagem de uma estrutura própria nas proximidades do mercado do Leste Europeu. A partir do momento em que se chegou à conclusão de que a aliança solucionaria, de forma mais econômica, o problema enfrentado, não houve mais a preocupação com o impacto sobre os acionistas.

Com relação aos armadores parceiros, verificou-se uma preocupação latente. De acordo com o executivo da empresa Global, por exemplo, foi feita uma análise profunda e abrangente para se verificar a possibilidade de atender a todas as necessidades da Cacique, e "um trabalho exaustivo para encontrar subsídios que pudessem garantir a relação custo/beneficio frente a alta administração." Também a empresa ff Alfa, que pretendia montar uma estrutura logística que garantisse sua entrada no tráfego Brasil - Rússia e que, segundo, as palavras do executivo, "estavam a espera do parceiro ideal", tinha uma avaliação profunda do impacto sobre os acionistas.

\subsection{AVALIAÇÃO DO PODER DE BARGANHA}

De acordo com o diretor de exportação da Cacique, desde o princípio, foi definido o nível de utilização das capacidades e competências dos parceiros. Assim, caberia aos Armadores - direta ou indiretamente - desempenhar as seguintes atividades: recebimento da carga em um armazém do porto; retirada dos contêineres vazios para estufamento da carga; estufamento da carga nos contêineres e entrega no costado do navio; transporte marítimo para a Europa e desembaraço da carga para o transbordo; armazenagem e aluguel dos contêineres na Europa; transporte marítimo para a Finlândia e desembaraço da carga; armazenagem e 
aluguel dos contêineres na Finlândia; transporte rodoviário para Moscou ou rodo-ferroviário para outros destinos do Leste Europeu e administração da localização dos contêineres (monitoramento) e dos transbordos necessários ate a entrega ao cliente, com emissão de relatórios diários para acompanhamento.

No que se refere à proteção dos recursos centrais da empresa, para o diretor de exportação da Cacique, o único recurso estratégico que se pretendeu proteger foi a informação. Assim, foi solicitado aos parceiros que não revelassem, em nenhuma hipótese, a quantidade de contêineres estocados na Europa. Para o citado diretor: "a quantidade de contêineres parados poderia dar a idéia aos clientes de falta de demanda do mercado e isso não e bom para os negócios”.

Para os parceiros da aliança não houve nenhum recurso que se pretendeu proteger.

Quanto ao estilo de negociação e aos antecedentes dos parceiros, de acordo com o diretor de exportação da Cacique, a empresa, por estar no mercado há mais de 40 anos, possui um conhecimento profundo dos armadores, baseado no relacionamento contínuo. Os armadores, por sua vez, por serem prestadores de serviço para vários destinos, tinham a Cacique em alto grau de consideração. Os parceiros perceberam a clareza de propósito que envolveu o processo de negociação da aliança. De acordo com eles, todos os participantes colocaram de forma transparente, desde o começo, o por que se interessavam em integrar a aliança.

Como as operações logísticas já estavam pré-determinadas pelas necessidades das partes diretamente envolvidas na distribuição do produto e, dada a grande movimentação de carga que os candidatos à parceria com a Cacique possuem na região, o que lhes dá condições de negociar prazos e tarifas de forma muito mais efetiva do que um exportador, pretendia-se encontrar um equilíbrio entre as capacidades-chave dos candidados, de forma a não deixar toda a operação da empresa nas mãos de um ou dois participantes, o que ficou evidenciado na seguinte frase: “A empresa sabia que quem tem um fornecedor não tem nenhum e quem tem dois tem apenas um. Então, ela necessitaria de, pelo menos, três fornecedores para que o seu processo não corresse o risco de sofrer descontinuidade."

A principal tarefa da Cacique foi fazer com que os três parceiros chegassem a números parecidos que justificassem uma divisão da sua carga. Para o diretor de exportação da Cacique, esta foi uma das tarefas mais difíceis, uma vez que os números apresentados por cada participante eram diferentes. Após varias reuniões, conseguiu-se chegar a um consenso. 
Os gerentes comerciais das empresas parceiras da Cacique ressaltaram a necessidade da formação de novas parcerias e ou alianças estratégicas com outras empresas localizadas na região alvo. Assim, as empresas Global e ff Beta efetivaram uma parceria com a administração do porto de Hamina, na Finlândia, baseada no interesse no volume embarcado pela Cacique. Para as outras operações associadas à armazenagem nos portos de Antuérpia e Hamburgo, ao transporte da mercadoria para o porto de Hamina e à distribuição da mercadoria para o destino final, também foram criadas alianças com parceiros locais. A Figura 3 apresenta a rede de alianças assim constituída.

\subsection{RESULTADOS}

A Cacique conseguiu fazer um estoque estratégico na Europa (Hamburgo e Antuérpia) e na Finlândia (Hamina ou Kokta), para pronta entrega, e, assim, continuar competitiva na região do Leste Europeu.

Os três parceiros da Cacique começaram a transportar mais carga, uma vez que os contêineres, anteriormente divididos entre cinco ou seis armadores, passaram a ser transportados por apenas três. Os parceiros ainda se beneficiaram, de um lado, da aliança com uma empresa exportadora de porte, com nome reconhecido no mercado global e, de outro, da criação de novas competências, através do desenvolvimento próprio ou da formação de novas alianças com empresas da região.

\section{CONCLUSÕES}

Diante da complexidade do ambiente competitivo do mercado internacional, a experiência da Cacique deixou patente, que a gestão das atividades logísticas possibilitou a recuperação da posição competitiva, sem a necessidade de incorrer em pesados investimentos associados à disponibilização "em tempo" do produto no mercado focal.

A coordenação das decisões e a cooperação entre o conjunto de organizações envolvidas no processo logístico foram os elementos centrais da estratégia implementada. A aliança estratégica entre a empresa exportadora e os prestadores de serviço logísticos constituiu-se em importante mecanismo de construção de novas capacidades e competências, superando as deficiências inerentes à atuação isolada de uma única organização.

As razões que levaram as empresas a se associarem traduziram-se na lógica de criação de valor, através da união de forças na construção de vantagens competitivas capazes de colocar as empresas participantes da aliança em posição privilegiada frente à concorrência. 
Nesse sentido, verificou-se claramente a complementaridade entre as partes, a qual deu origem a um efeito sinérgico. Ademais, as questões relacionadas com o mercado e com a posição que a Cacique nele ocupa foram incorporadas aos objetivos das empresas parceiras, revelando uma clara visão da interdependência estratégica no interior da cadeia de suprimentos.

Por sua vez, ficou evidenciado que a aliança original entre a Cacique e os prestadores de serviço logísticos, deu origem a novas alianças entre os últimos e empresas localizadas no Leste Europeu, configurando a formação de uma rede de alianças estratégicas, ampla e complexa. Assim, a atuação no mercado internacional exige a "cooperação multilateral", a qual representa um desafio associado aos problemas derivados do alinhamento estratégico de múltiplos parceiros.

A experiência da Cacique revelou, também, que o sucesso da formação de uma aliança está baseado na identificação e seleção de parceiros, a partir de uma análise aprofundada de competências e recursos, voltada ao efetivo alinhamento de interesses e de estratégias. Nesse âmbito, os objetivos devem ser claramente definidos e compartilhados entre os parceiros; as estratégias das empresas envolvidas devem ser compatíveis entre si; os benefícios associados à aliança devem ser identificados, tornando transparentes as oportunidades inerentes a cada um; clara definição daquilo que será requerido de cada parceiro e quais os benefícios cada um recebera em troca e, especialmente, a importância do respeito que deve envolver o processo de avaliação.

Em outras palavras, identificar claramente quais são as oportunidades que a aliança está criando e qual posição está garantindo aos parceiros, dentro do ambiente competitivo. $\mathrm{O}$ estudo do caso estudado indica que, na construção da confiança e do comprometimento entre os agentes, o tratamento igualitário e a transparência na negociação exercem papel essencial. Quando as partes agem compartilhando benefícios, responsabilidade e riscos, a confiança aumenta, reduzindo a possibilidade de comportamentos oportunistas.

As limitações do estudo estão asssociadas, em primeiro lugar, à realização de entrevistas somente com os executivos ligados à formação da aliança, não abrangendo os demais funcionários e os acionistas. Em segundo lugar, a impossibilidade de entrevistar os executivos das empresas envolvidas com as alianças constituídas na Europa.

Podem ser visualizadas duas grandes direções, no âmbito de futuras pesquisas. Em primeiro lugar, embora o estudo sugira que o comprometimento dos agentes é um dos elementos centrais do sucesso de uma aliança estratégica, não abordou a análise dos conflitos 
e de como a sua administração pode reforçar o comprometimento. Nesse sentido, considerando que a suspeita e o oportunismo são elementos presentes na formação de uma aliança, é importante investigar o processo de gestão do conflito no interior da relação como elemento nuclear do sucesso da aliança. Em segundo lugar, considerando a complexa rede de alianças constituída a partir da aliança nodal, é fundamental a investigação do processo de coordenação e controle da multiplicidade de agentes envolvidos. 


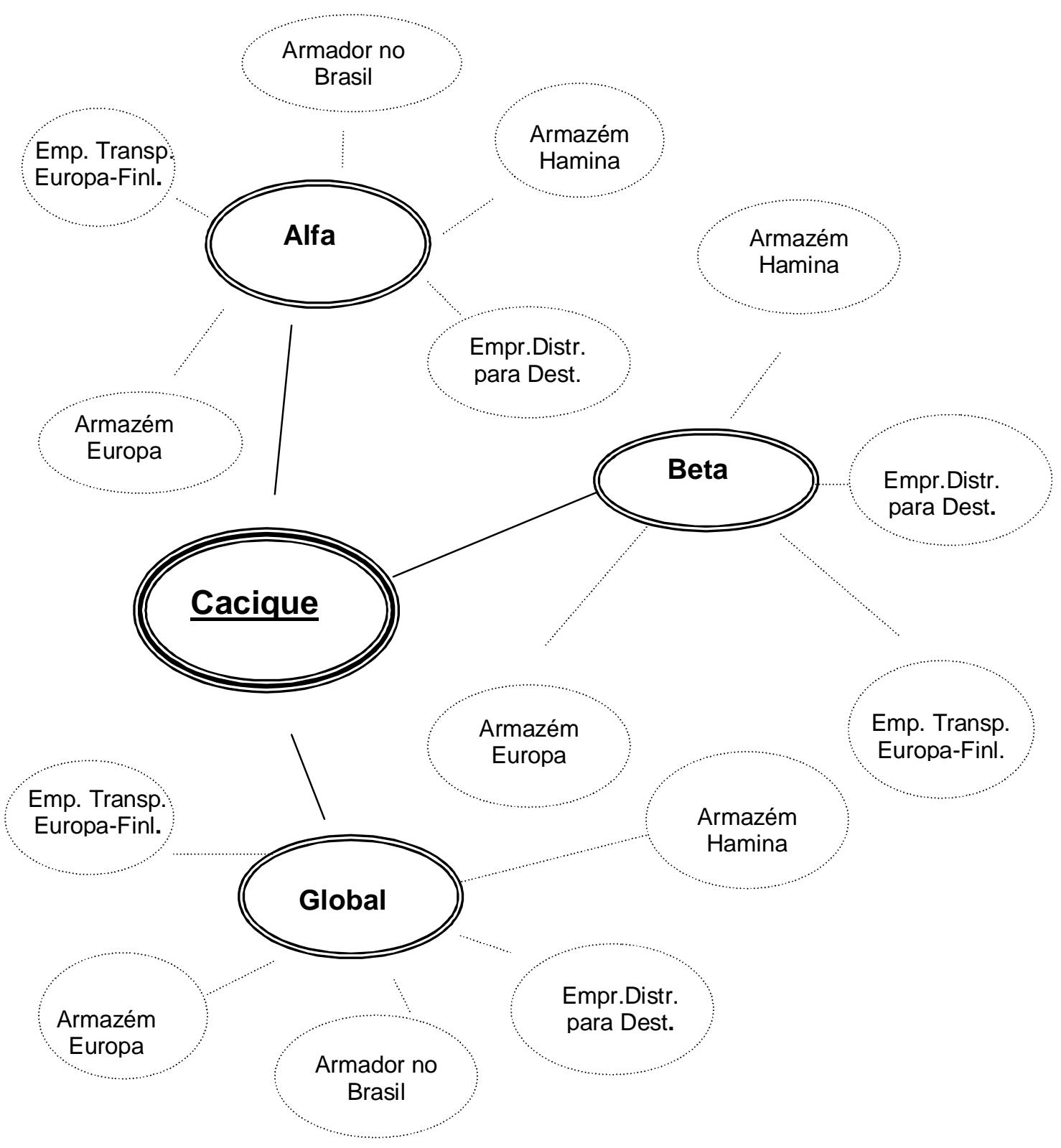

Figura 3 : Visão geral dos relacionamentos entre os participantes das parcerias Fonte: elaboração dos autores 


\section{REFERÊNCIAS}

BARNEY, J.B. Firm resources and sustained competitive advantage. Journal of Management,v.17,n.1,p.99-120,1991.

BOWERSOX, D.J. The Strategic Benefits of Logistics Alliances. Harvard Business Review, v. 68, n. 4 , p. $36-45,1990$.

BOWERSOX, D.J. et al. Leading Edge Logistics: Competitive Positioning for the 1990's,

Oak Brook, IL: Council of Logistics Management, 1989.

BOWERSOX, D.J., MENTZER, J.T. e SPEH, T.W. Logistics leverage. Journal of Business Strategies, v. 12, n. 2, p. 36-49, 1995.

CARLISLE, J. e PARKER, R. Beyond Negotiation: Redeeming Customer-Supplier Relationships. Chichester: Wiley, 1989.

COOKE, J.A Third-party logistics: Has its time come? Traffic Managment, v. 33, n. 10, p. 71-74, 1994.

Cox, A. The art of the possible: Relationship management in power regimes and supply chains. Supply Chain Management: An International Journal, v. 9, n. 5, p. 346-356, 2004.

CROOM, S. The dyadic capabilities concept: examining the process of key supplier involvement in collaborative product development European Journal of Purchasing and Supply Management, v. 7, n. 1, p.29-37, 2001.

DOZ, Y.L. e HAMEL, G. A vantagem das Alianças: A arte de criar valor através de parcerias. Rio de Janeiro: Qualitymark Editora, 2000.

ELLRAM, L. e COOPER, M. Characteristics of supply chain management and the implications for purchasing and logistics strategy. International Journal of Logistics Management,v.4,n.2,p.1-10,1993.

FORD, D. The development of buyer-supplier relationships in industrial markets. European Journal of Marketing, v 14 (5/6), p 339-53, 1980.

FORD, D. et al.. Make or buy decisions and their implications for buying, marketing and technology strategy. Industrial Marketing Management, v.23, n. 3, p 207-214, 1993.

FRANKEL, R, WHIPPLE, J.S e FRAYER, D.J. Formal versus informal contracts: achieving alliance Sucess. International Journal of Physical Distribution \& Logistics Management, v 26, n. 3, p 47-64, 1996. 
GARDNER, J. e M.C. COOPER, M. Elements of Strategic Partnership. In: McKeon, J.E. (ed)Partnerships: A Natural Evolution in Logistics, Cleveland, OH: Logistics Research, Inc., p. 15-32, 1988.

GOOLEY, T.B.Dual perspectives. Logistics Management, v. 44 , n. 1, p. 52-55, 2005.

HARBISON, J. R e PEKAR, P. Alianças Estratégicas: Quando a parceria e a alma do negócio e o caminho para o sucesso. São Paulo: Futura, 1999.

HOLWEG, M. e BICHENO, J. Supply chain simulation - A tool for education, enhancement and endeavour. International Journal of Production Economics, v. 78, p. 163-175, 2002.

HOYT, J. e HUQ, F. From arms length to collaborative relationships in the supply chain: an evolutionary process. International Journal of Physical Distribution and Logistics Manangement, v. 30, n. 9, p.750-764, 2000.

INNIS, D.E. e LA LONDE, BJ. Customer service: the key to customer satisfaction, customer loyalty and market share.Journal of Business Logistics, v.15, n. 1, p.1-27, 1994. JOHANSON, J. e MATTSSON, L. G. The markets as networks research tradition in Sweden. In: Laurent, G., Lilien, G.L. e Pras, B.(eds.) Research traditions in marketing. Helsink: Kluwer, p. 321- 342, 1994.

KNEMEYER, A.M. e MURPHY, P.R. Is the glass half full or half empty? An examination of user and provider perspectives towards third-party logistics relationships. International Journal of Physical Distribution and Logistics Management, v. 35, n. 9/10, p. 708-727, 2005 .

LALONDE, B.J. e COOPER, M.C. Partnerships in Providing Customer Service: A ThirdParty Perspective Oakbrook, IL: Council of Logistics Management, 1989.

LAVIE, D. Capability reconfiguration: an analysis of incumbent responses to technological change. Academy of Management Review, v. 31, n. 1, p. 153-174, 2006.

LORANGE, P. e ROOS, J. Alianças Estratégicas: Formação, implementação e evolução. São Paulo: Atlas, 1995.

MACPHERSON, A. Corporate Directions in Supply Chain Management: Implications for SME Competences and Inter-Organisational Relations. Working Paper Series, 22, Business School of the Manchester Metropolitam University, Manchester, julho, 2001. Disponível em: http://www.ribm.mmu.ac.uk/wps/papers/01-15.pdf. Acessado em 20 de janeiro de 2008. MILES, M. e HUBERMAN, A. Qualitative Data Analysis: An Expanded Sourcebook, NewBury, Beverly Hills: Sage, 1994. 
MIN, S. e MENTZER, G. Developing and Measuring Supply Chain Management Concepts. Journal of Business Logistics, v. 25, n. 1, p. 63-99, 2004.

NEVES, J. L. Pesquisa Qualitativa: Características, Usos e Possibilidades. Cadernos de Pesquisa em Administração, v. 1, n. 3, FEA-SP, São Paulo, segundo semestre, p. 1-5,1996. NOLETO, M.J. Parcerias e Alianças Estratégicas: Uma Abordagem Prática. São Paulo: Global,2000.

OLAVARRIETA, S. E. e ELLINGER, A. E. Resource-based theory and strategic logistics research. International Journal of Physical Distribution \& Logistics Management. v. 27, n. 9-10, p. 559-588, 1997.

SCHOEMAKER, P.J. e AMIT, R.H. Investment in strategic assets: industry and firm-level perspectives. In: Schultz, D., Lauterborn, R. e Tannenbaum, S. (Eds)Integrated Marketing Communications, New York, NY: NTC Business Books, 1994.

STEFANSSON, G. Collaborative logistics management and the role of third-party service providers. International Journal of Physical Distribution and Logistics Management, v. 36, n. 2, p. 76-92, 2006.

TOKMAN, M. et al. Exploration, Exploitation and Satisfaction in Supply Chain Portfolio Strategy. Journal of Business Logistics, v. 28, n.1, p. 25-56, 2007.

WILKINSON, I.F., MATTSSON, L.G. e. EASTON, G. International Competitiveness and Trade Promotion Policy from a Network Perspective. Journal of World Business, v.35, n. 3, p.275-289, 2000.

WINTER, S.G.Understanding dynamic capabilities. Strategic Management Journal, v. 24, n. 10, p. 991-995, 2003.

YIN, R. Estudo de Caso: planejamento e métodos. Tradução de Daniel Gassi, 2a ed. Porto Alegre: Bookman, 2001. 